\title{
Pengurangan Hambatan Aliran pada Celah Silinder Koaksial Akibat Slip
}

\author{
Yanuar, Gunawan dan M. Baqi \\ Departemen Teknik Mesin, Fakultas Teknik Universitas Indonesia, Depok \\ Email: Yanuar@eng.ui.ac.id
}

\begin{abstract}
ABSTRAK
Efek slip yang terjadi pada dinding akibat lapisan zat penolak air dapat mengurangi kerugian jatuh tekanan. Dengan melapisi dinding silinder putar pada bagian dalam koaksial viskometer slip akan terjadi. Tujuan penelitian untuk membuktikan berkurangnya hambatan aliran (torsi) pada silinder dan koefisien kecepatan slip akibat pelapisan zat penolak air pada dinding. Zat teflon dan wax (lilin) digunakan untuk melapisi permukaan dinding. Sudut kontak butiran air dengan dinding yang dilapisi teflon dan wax masing-masing sekitar $110^{\circ}$ dan $130^{\circ}$. Rasio jari-jari silinder dalam dan silinder luar adalah 0,932 dan 0,676. Larutan glicerin dengan konsentrasi $60 \%, 70 \%$ dan $80 \%$ wt sebagai fluida uji. Pengurangan hambatan maksimum yang terjadi yaitu $12 \%$ untuk larutan glicerin $80 \% w t$ pada rasio jari-jari 0,932. Analisa perhitungan dari koefisien momen dibandingkan dengan nilai koefisien momen dari percobaan menunjukkan kesesuaian.
\end{abstract}

Kata kunci: Koaksial silinder, koefisien kecepatan slip, zat penolak air, larutan gliserin, sudut kontak.

\begin{abstract}
Slip effect which occurs at the wall due to the layer of water repellent wall can reduce the pressure drop. The highly water repellent wall coating on the inside coaxial viscometer slip will be occur. The aim of experiment is proving drag reducing of the torque on the cylinder and the coefficient of velocity slip due to the water repellent coating on the wall. Teflon and wax materials are used to coat the surface of the wall. Contact angle of water droplets with a Teflon-coated walls and waxed each of about $110^{\circ}$ and $130^{\circ}$ into flat surface. The ratio of the radius of inner cylinder and outer cylinder are 0.932 and 0.676. Glycerin solution with concentration $60 \%, 70 \%$ and $80 \%$ wt used the test fluid. The maximum drag reduction occurred is $12 \%$ for $80 \%$ wt glycerin solution at the 0.932 ratio of the radius. The calculation analysis of the moment coefficient fit with experimental data.
\end{abstract}

Keywords: Coaxial cylinder, velocity slip coefficient, highly water repellent wall, glycerin solution, contact angle.

\section{PENDAHULUAN}

Fluida Newtonian slip pada batas padat (solid boundary) biasanya diabaikan. Hasil perhitungan tanpa slip tidak memiliki perbedaan yang berarti dengan hasil percobaan. Jika slip yang terjadi pada batas padat tadi diperhitungkan, maka dapat dikeetahui pengurangan hambatan baru baik pada aliran Newtonian dan non-Newtonian. Watanabe [1] telah meneliti tentang slip yang terjadi pada batas padat aliran dalam pipa kotak dengan meneliti kerugian jatuh tekanan yang terjadi. Pengurangan hambatan aliran laminar terbesar yang terjadi pada penelitian tersebut yaitu 23\%. Watanabe [2] juga melaporkan pengurangan hambatan aliran laminar fluida Newtonian pada pipa bulat dengan melapisi zat penolak air (highly water repellent wall) dan membuktikan adanya kecepatan slip pada dinding dengan menggunakan fluida Newtonian. Meskipun fenomena slip merupakan salah satu dasar dari ilmu mekanika fluida, tetapi masih sedikit penelitian yang berkaitan dengan hal tersebut. Bentuk aliran pada koaksial viscometer sangat menarik untuk diketahui hubungan antara cairan dengan permukaan dinding solid. Aliran diantara dua silinder putar dikenal aliran Couette (Couette flow) [7]. Yamada [3] memperlihatkan data percobaan koefisien torsi pada dua silinder koaksial 
putar. Nouri dan Whitelaw [4] melaporkan pengukuran tekanan dan kecepatan fluida Newtonian dan non-Newtonian dengan konsentris annulus pada nilai Reynolds tinggi atau aliran turbulen sempurna. Tujuan penelitian untuk membuktikan berkurangnya hambatan aliran (torsi) pada silinder dan koefisien kecepatan slip akibat pelapisan zat penolak air pada dinding. Zat teflon dan wax (lilin) digunakan untuk melapisi permukaan dinding.

\section{METODE PENELITIAN}

Pada aliran laminar kecepatan konstan (steady state), tegangan geser dan komponen arah $\theta$ dapat diturunkan dari persamaan Navier [8] - Stokes [5]:

$$
\begin{gathered}
\tau_{r \theta}=\mu\left[r \frac{\partial}{\partial r}\left(\frac{v_{\theta}}{r}\right)\right] \\
0=\frac{d}{d r}\left[\frac{1}{r} \frac{d}{d r}\left(r v_{\theta}\right)\right]
\end{gathered}
$$

Dimana $\mu$ dan $v_{\theta}$ masing-masing adalah viskositas dan kecepatan pada komponen $\theta$. Jika slip terjadi pada dinding silinder dalam, kondisi batas adalah:

$$
\begin{aligned}
& r=k R_{o} ; v_{\theta}=u_{s} \\
& r=R_{o} ; \quad v_{\theta}=\omega_{o} R_{o}
\end{aligned}
$$

dimana $u_{s}$ dan $\omega_{0}$ masing-masing adalah kecepatan slip pada dinding silinder dalam dan kecepatan sudut pada silinder luar. Profil kecepatan $v_{\theta}$ dihitung menggunakan Persamaan 4:

$v_{\theta}=\frac{k R_{o}}{r} u_{s}+\frac{R_{o} \omega_{o}-k u_{s}}{\left(1-k^{2}\right) R_{o} r}\left(r^{2}-k^{2} R_{o}^{2}\right)$

Dengan mensubstitusikan Persamaan 4 ke Persamaan 1, kita mendapatkan torsi $\mathrm{T}$ yang diperlukan untuk menjalankan shaft luar:

$$
T=4 \pi \mu R_{o}^{2} L\left(\omega_{o} k-u_{s} \frac{1}{R_{o}}\right)\left(\frac{k}{1-k^{2}}\right)
$$

Sehingga hubungan kecepatan slip dengan torsi adalah:

$$
u_{s}=R_{o} k \omega_{o}-\frac{T}{4 \pi \mu R_{o} L} \frac{\left(1-k^{2}\right)}{k}
$$

Dengan memasukkan hasil pengukuran $\mathrm{T}$ ke dalam Persamaan 6, kecepatan slip dapat diketahui. Navier [8] juga berhasil mendapatkan hubungan antara kecepatan slip dengan tegangan geser:

$$
\left.\tau_{r \theta}\right|_{r=k R_{o}}=\beta u_{s^{\prime}}
$$

dimana $\beta$ adalah koefisien kecepatan slip. Persamaan 6 dimodifikasi dengan persaman 7, menghasilkan persamaan: $u_{s}=\frac{2 \mu R_{o} k \omega_{o}}{\beta k R_{o}\left(1-k^{2}\right)+2 \mu}$

Koefisien torsi yang bekerja pada silinder dalam, $\mathrm{Cm}$ didapat dari persamaan:

$C m=\frac{16 k^{2}}{(k+1)^{4}}\left(1-\frac{2}{\frac{\beta R_{o}}{\mu} k\left(1-k^{2}\right)+2}\right) / R_{\omega}$

Cm didefinisikan sebagai $C m=T / 2 \pi \rho R_{m}^{4} \omega_{o}^{2} L$ bila slip tidak terjadi, kita mendapatkan persamaan baru, dengan memasukkan nilai $\beta=\infty$ ke dalam Persamaan 9

$$
\begin{aligned}
& C m=\frac{16 k^{2}}{(k+1)^{4}} / R_{\omega}=\frac{16\left(1-\delta / R_{o}\right)^{2}}{2^{4}\left(1-\delta / 2 R_{o}\right)^{4}} / R_{\omega} \\
& C m=\frac{\left(1-\delta / R_{o}\right)^{2}}{\left(1-\delta / R_{0}+\left(\delta / 2 R_{0}\right)^{2}\right)^{2}} / R_{\omega}
\end{aligned}
$$

dimana $\delta$ adalah jarak antara silinder luar dengan bob (silinder dalam). Pada kasus $\left(\delta / R_{o}\right)^{2}=0$, kita dapatkan $\mathrm{Cm}=1 / R_{\omega}$. Untuk jarak yang kecil, nilai dari $\left(\delta / R_{0}\right)^{2}$ adalah sangat kecil sehingga bisa disamakan dengan perhitungan Cm ketika jarak $=0$.

Percobaan dilakukan untuk menghitung torsi pada aliran laminar larutan gliserin diantara dua silinder koaksial putar. Silinder yang berputar yaitu silinder luar.

Gambar 1 menunjukkan sketsa eksperimental set-up alat uji koaksial silinder putar terdiri dari 2 buah tabung silinder. Tabung luar dengan diameter $=100 \mathrm{~mm}$, tinggi $=350 \mathrm{~mm}$ dan tebal $=3 \mathrm{~mm}$.

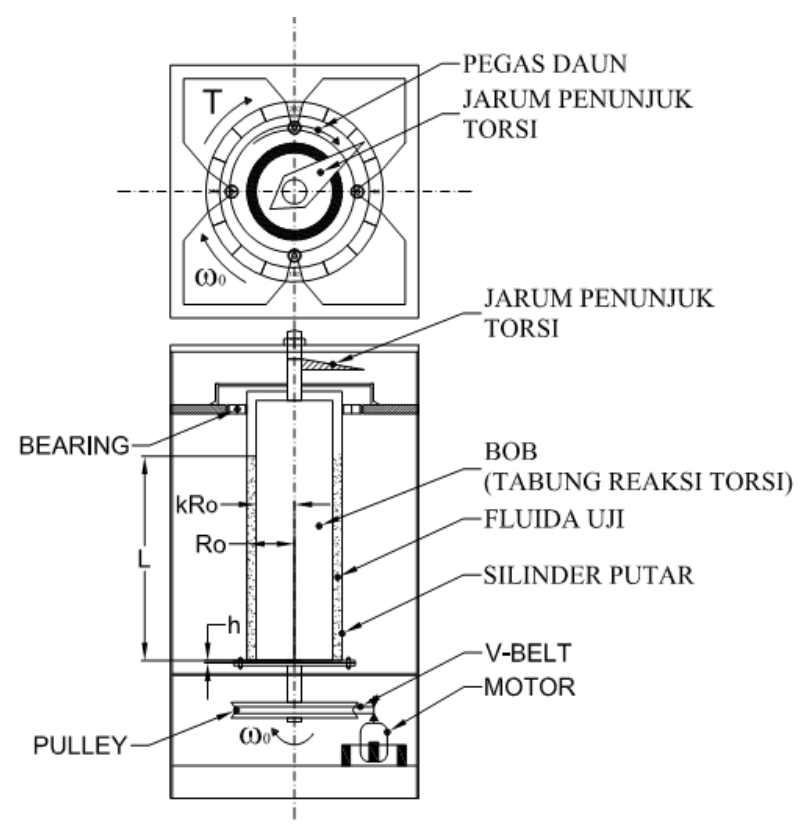

Gambar 1. Sketsa Eksperimental Set-Up 
Dudukan tabung terdiri dari plat (290 x 110) $\mathrm{mm}$, bearing dengan diameter 2" (Inch) dan lubangnya diameter $14 \mathrm{~mm}$ serta sebuah poros diameter $14 \mathrm{~mm}$ dan panjang $150 \mathrm{~mm}$. Motor penyangga dari pegas yang dibungkus karet dan diletakkan diatas sebuah papan kayu berukuran (282 x 160) mm. Variasi diameter puli (pulley) adalah 2", 3", 7" dan 9" yang digunakan untuk mendapatkan variasi kecepatan sudut putar. Kombinasi diameter puli tersebut menghasilkan 8 macam kecepatan sudut putaran (lihat Tabel 1). Alat tachometer digunakan sebagai kontrol kecepatan putar.

Tabung reaksi torsi (bob) terbuat dari teflon dan dilapisi lilin dengan diameter $80 \mathrm{~mm}$ bebas berputar dikaitkan dengan pegas pengukur torsi untuk mengukur torsi akibat efek pergeseran fluida uji [5]. Pegas untuk mengukur torsi terbuat dari kawat baja dengan diameter $1 \mathrm{~mm}$ digunakan untuk mengukur perubahan nilai torsi putaran. Temperatur fluida larutan gliserin dijaga konstan pada $27^{\circ} \mathrm{C}$.

Motor listrik dengan putaran poros motor konstan pada 820 rpm, bila putaran poros dihubungkan antara variasi diameter puli $\mathrm{d}_{1}=2$ " dengan $\mathrm{d}_{2}=3$ " akan menghasilkan putaran tabung bagian luar adalah $540 \mathrm{rpm}$, dan selanjutnya variasi kecepatan putar dapat ditentukan dengan cara variasi diameter puli yang dihubungkan, hasil dari variasi kecepatan sudut dapat dilihat dalam Tabel 1. Tabung bagian dalam diatasnya diletakkan pegas untuk mengukur pergerakan jarum sebagai torsi. Fluida uji dimasukkan diantara tabung setinggi 250 $\mathrm{mm}$ untuk diuji. Efek gesekan fluida yang terjadi akan menggerakkan tabung bagian dalam sesuai dengan skala kecepatan sudut yang diberikan. Pegas pengontrol jarum torsi akan bergerak sebagai nilai torsi yang ditimbulkan oleh variasi putaran sudut. Kalibrasi torsi dilakukan dengan mengambil data torsi yang terjadi untuk fluida air murni yang sudah umum diasumsikan sebagai standart.

Tabel 1. Variasi Diameter Puli Untuk Mendapatkan Kecepatan Sudut (rpm)

\begin{tabular}{|c|c|c|c|c|}
\hline$d_{1} d_{2}$ & 2" & 3" & 7"' & 9" \\
\hline 2" & $\mathrm{X}$ & 540 & 230 & 180 \\
\hline 3" & 1230 & $\mathrm{x}$ & $\mathrm{x}$ & 270 \\
\hline 7" & X & 1820 & $\mathrm{x}$ & 635 \\
\hline 9" & $\mathrm{X}$ & $\mathrm{x}$ & 1050 & $\mathrm{X}$ \\
\hline
\end{tabular}

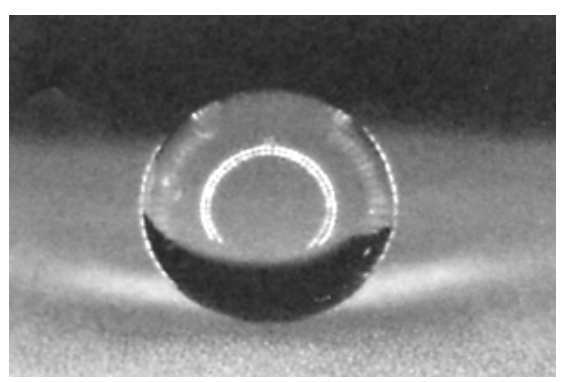

Gambar 2. Bentuk Tetesan Glicerin pada Permukaan Lilin
Gambar 2 menunjukkan hasil foto tetesan glycerin diatas permukaan rata yang dilapisi zat lilin. Sudut kontak antara permukaan rata dengan batas butiran sekitar $110^{\circ}$ untuk permukaan zat Teflon dan $130^{\circ}$ untuk zat lilin.

\section{HASIL DAN PEMBAHASAN}

Gambar 3 memperlihatkan kurva aliran untuk $70 \%$ wt gliserin. Garis lurus merupakan hasil percobaan fluida Newtonian. Hasil yang didapatkan menunjukkan hubungan linear antara tegangan geser dengan gradien kecepatan sehingga larutan gliserin tersebut merupakan fluida Newtonian.

Gambar 4 dan 5 memperlihatkan pengaruh viskositas dan rasio jari-jari terhadap terhadap kecepatan slip yang terjadi. Grafik antara tegangan geser pada dinding dengan kecepatan slip menunjukkan hubungan yang linear baik pada Gambar 4 maupun 5. Dari grafik tersebut dapat disimpulkan juga bahwa nilai koefisien kecepatan slip ( $(3)$ konstan. Nilai koefisien kecepatan slip tersebut merupakan gradien dari grafik yang didapat. Dari grafik juga terlihat bahwa nilai $\beta$ semakin naik seiring dengan kenaikan viskositas dan rasio jari-jari pada bob. $\beta$ adalah sebuah konstanta tak berdimensi, dimana $\beta$ tersebut berhubungan dengan gesekan antara fluida dengan permukaan dinding. Jangkauan nilai $\beta$ pada percobaan ini yaitu berkisar antara 205-320 Pa.s/m [2].

Gambar 6, 7 dan 8 merupakan grafik hubungan nilai $\mathrm{Cm}$ dengan bilangan Reynolds. Garis lurus penuh merupakan nilai $\mathrm{Cm}$ tanpa slip, sesuai persamaan $\mathrm{Cm}=1 / R_{\omega}$. Sedangkan garis putus-putus merupakan grafik dari Persamaan 9 yang merupakan perhitungan $\mathrm{Cm}$ dengan slip. Dari grafik tersebut juga terlihat, untuk dinding Teflon tanpa lapisan lilin, memiliki nilai $\mathrm{Cm}$ berhimpit dengan garis lurus penuh. Nilai $\mathrm{Cm}$ dari percobaan dengan penambahan lapisan lilin pada dinding bob, mendapatkan nilai $\mathrm{Cm}$ yang lebih rendah dari nilai $\mathrm{Cm}$ tanpa penambahan lapisan lilin.

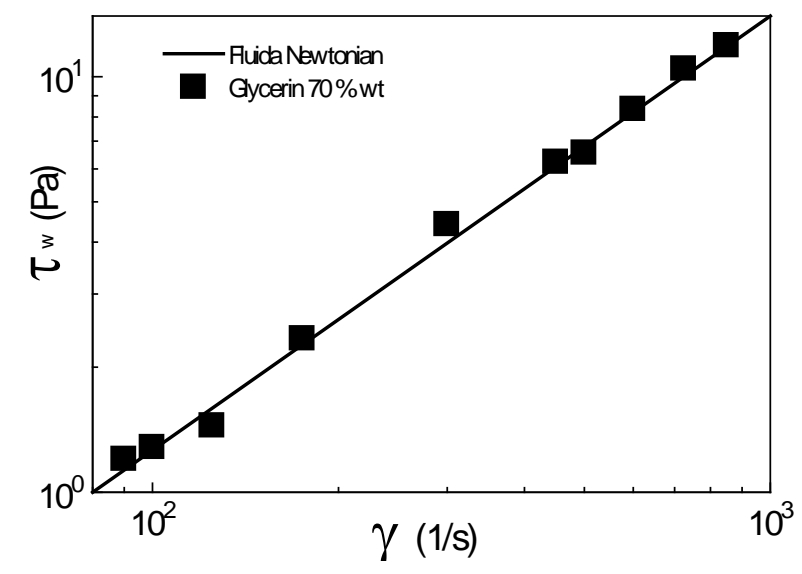

Gambar 3. Kurva Aliran Larutan Gliserin 70\% wt 


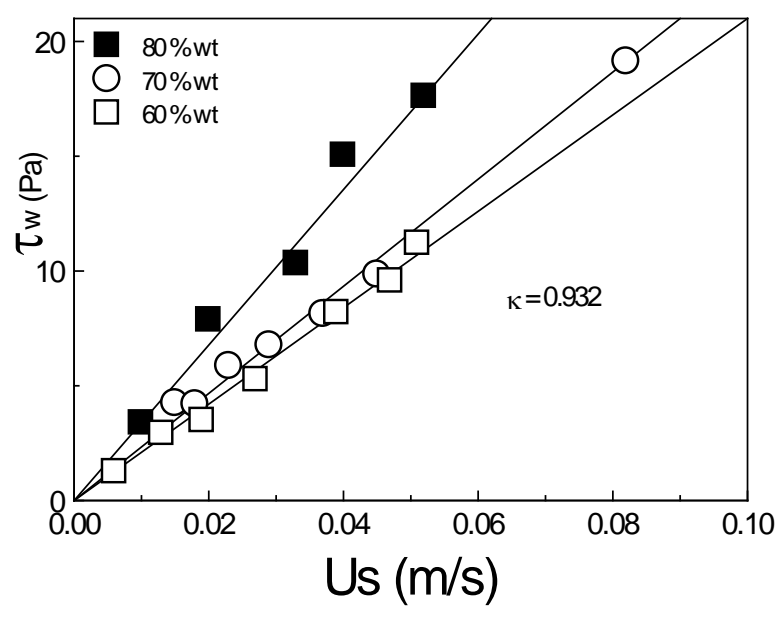

Gambar 4. Pengaruh Konsentras Larutan pada Kecepatan Slip

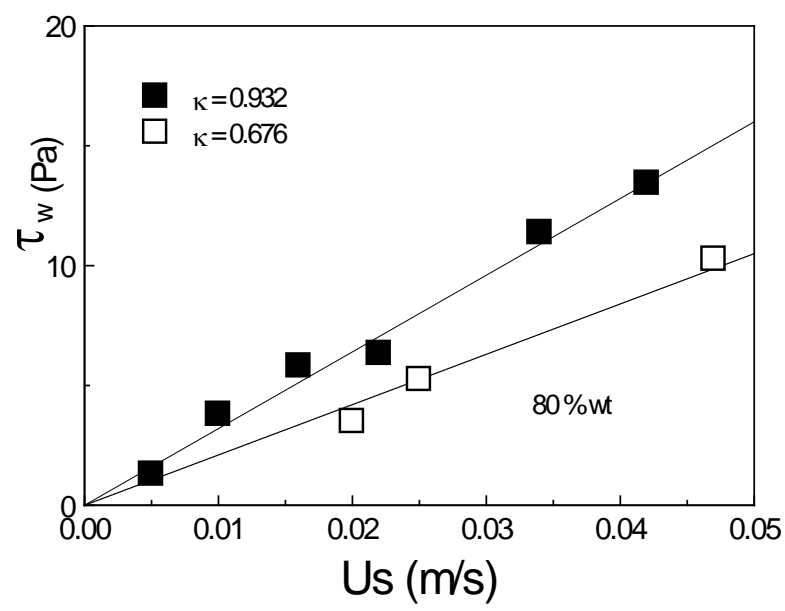

Gambar 5. Pengaruh Rasio Jari-Jari pada Kecepatan Slip

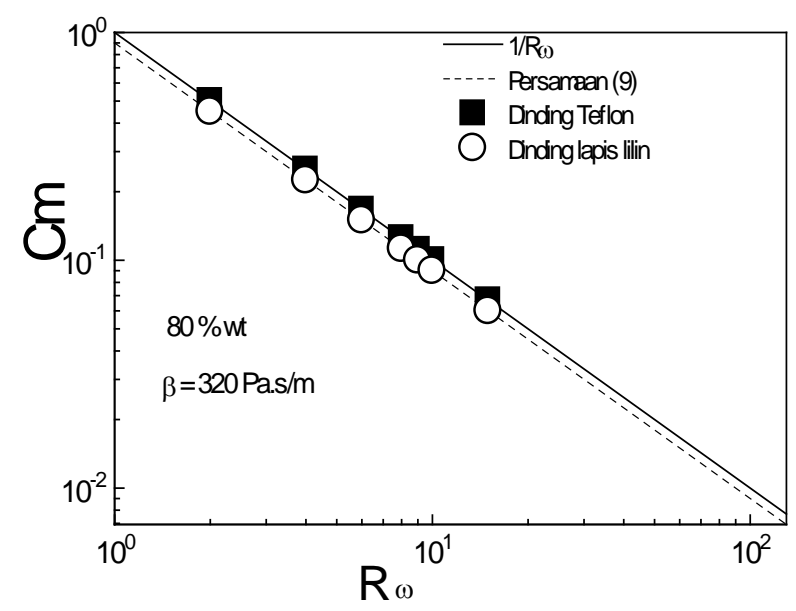

Gambar 6. Hubungan Antara Koefisien Momen dan Bilangan Reynolds pada Konsentrasi $80 \%$ Gliserin

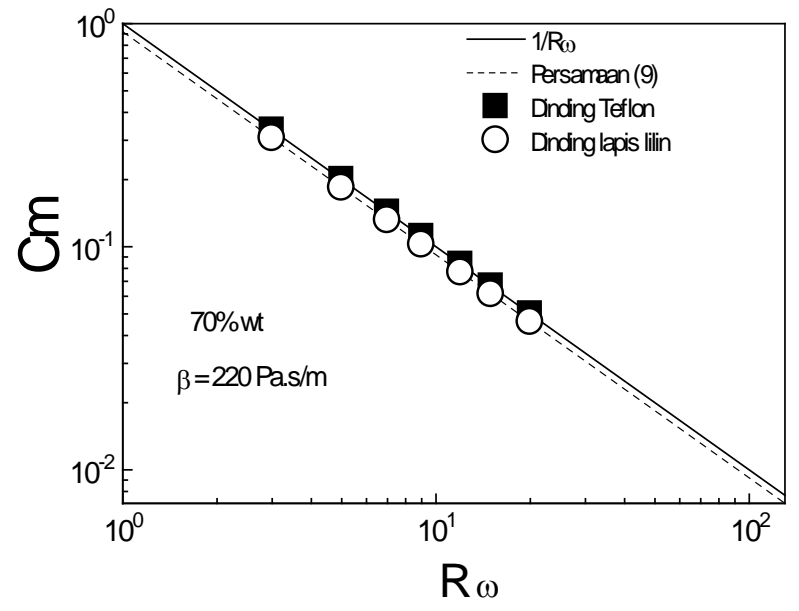

Gambar 7. Hubungan Antara Koefisien Momen dan Bilangan Reynolds pada Konsentrasi 70\% Gliserin

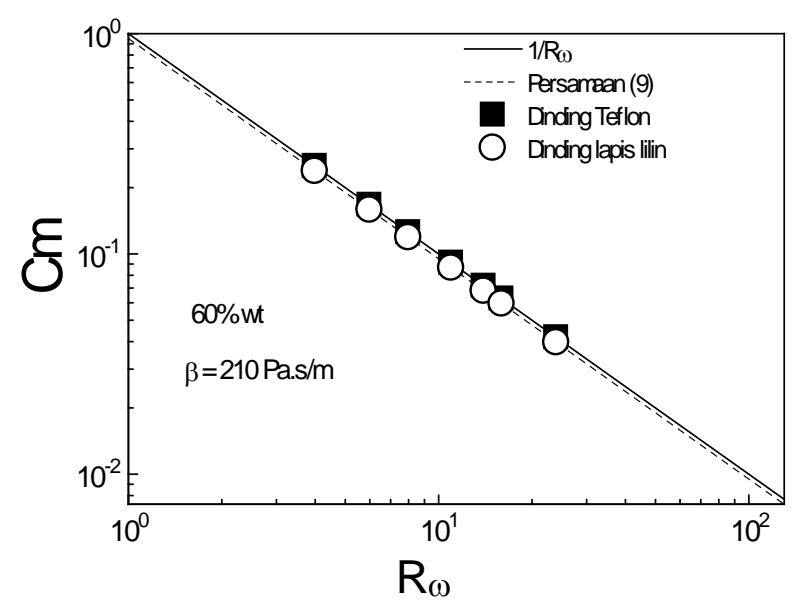

Gambar 8. Hubungan Anatara Koefisien Momen dan Bilangan Reynolds pada Konsentrasi 60\% Gliserin

Data hasil percobaan dengan penambahan lapisan lilin cenderung lebih rendah daripada tanpa penambahan lapisan lilin. Hal ini berkaitan dengan terjadinya pengurangan hambatan pada aliran tersebut. Untuk mendapatkan nilai pengurangan hambatan, maka digunakan persamaan sebagai berikut:

$\varepsilon=\left|\frac{\left.C_{m}\right|_{n}-\left.C_{m}\right|_{s}}{\left.C_{m}\right|_{s}}\right| \times 100 \%$

dimana indeks $\mathrm{n}$ dan $\mathrm{s}$ adalah permukaan tanpa lapisan lilin dan dengan lapisan lilin.

Gambar 9 memperlihatkan fenomena pengurangan hambatan yang terjadi pada larutan gliserin. Nilai pengurangan hambatan tersebut dipengaruhi oleh konsentrasi gliserin dan rasio jari-jari. 
Semakin tinggi konsentrasi, semakin tinggi pula yang terjadi, begitu pula pada rasio jari-jari. Pengurangan hambatan tertinggi terjadi pada larutan gliserin $80 \%$, rasio jari-jari $=0,932$ yaitu sebesar $12 \%$. Untuk rasio jari-jari 0,676 pengurangan hambatan yang terjadi lebih rendah, bahkan untuk konsentrasi gliserin 70 dan 60\%, tidak terjadi pengurangan hambatan.

Gambar 10 memperlihatkan hubungan antara koefisien kecepatan slip dan konsentrasi gliserin yang dipakai. Semakin tinggi konsentrasi, semakin tinggi pula nilai koefisien kecepatan slip yang terjadi.

Gambar 11 memperlihatkan nilai pengurangan hambatan pada variasi bilangan Reynolds tertentu. Nilai pengurangan hambatan semakin naik seiring kenaikan konsentrasi. Namun, tidak terjadi perubahan yang berarti ketika bilangan Reynolds nya berubah.

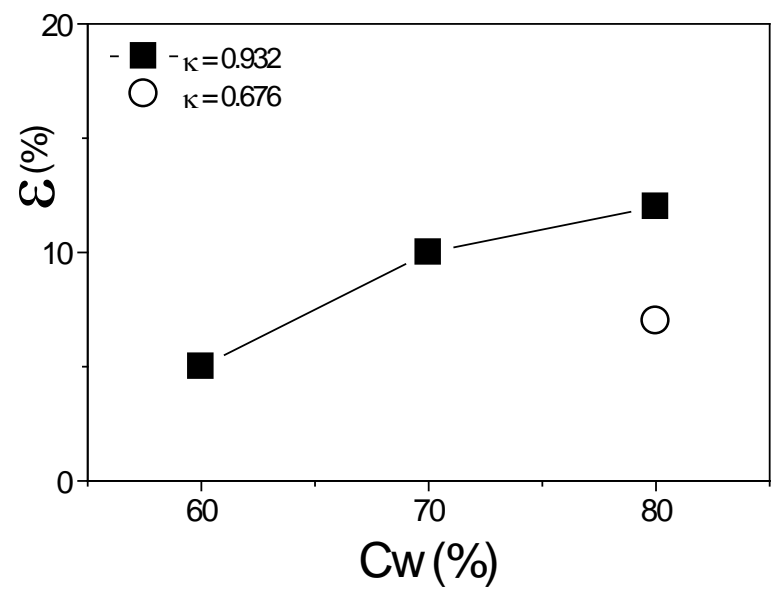

Gambar 9. Pengaruh Konsentrasi Larutan Gliserin pada Rasio Pengurangan Hambatan

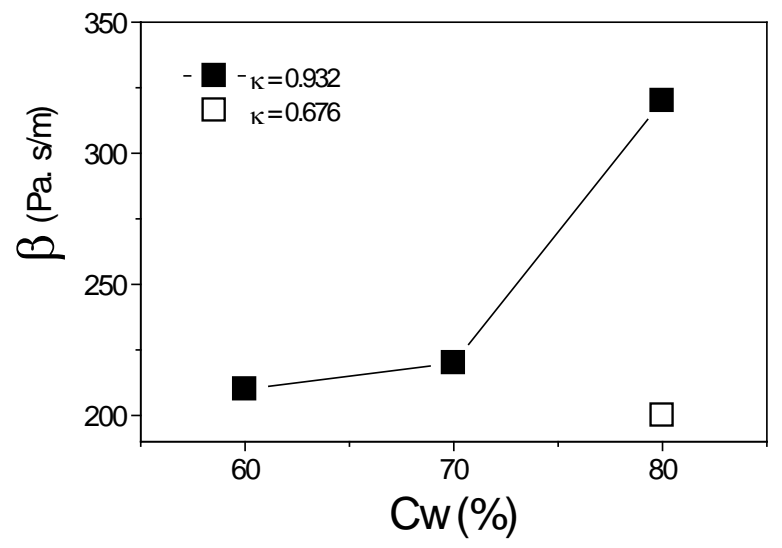

Gambar 10. Pengaruh Konsentrasi Larutan Gliserin pada Koefisien Kecepatan Slip

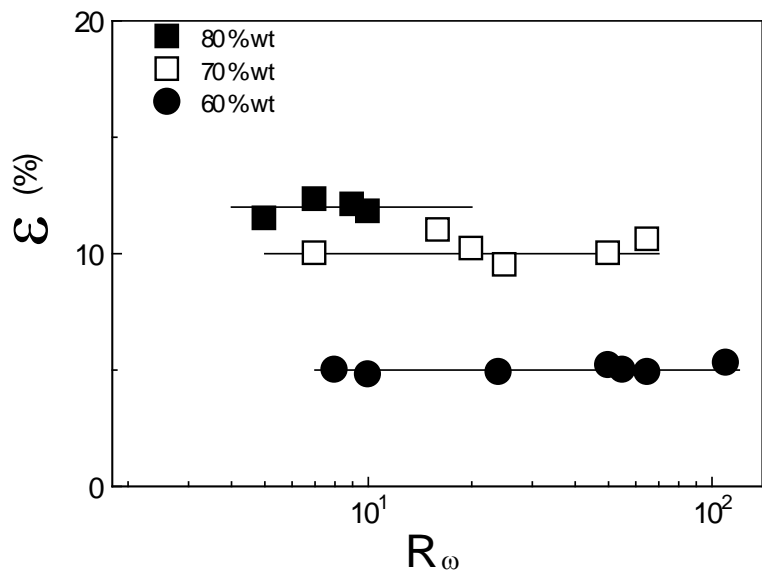

Gambar 11. Hubungan Pengurangan Hambatan dan Bilangan Reynolds

\section{KESIMPULAN}

Pengurangan kerugian jatuh tekanan terjadi pada dinding silinder yang dilapisi dengan zat penolak air (highly water repellent wall). Nilai drag reduction sekitar $12 \%$ terjadi pada larutan gliserin $80 \% w t$ dengan nilai $\mathrm{k}=0,932$. Analisa koefisien kecepatan slip hasil perhitungan dan koefisien kecepatan slip hasil penelitian menunjukkan hasil yang sama.

\section{Ucapan Terima Kasih}

Mengucapkan terima kasih kepada Sdr. Hudi, Alumni S1 DTM FT UI 08/09 atas bantuannya menyelesaikan penelitian ini.

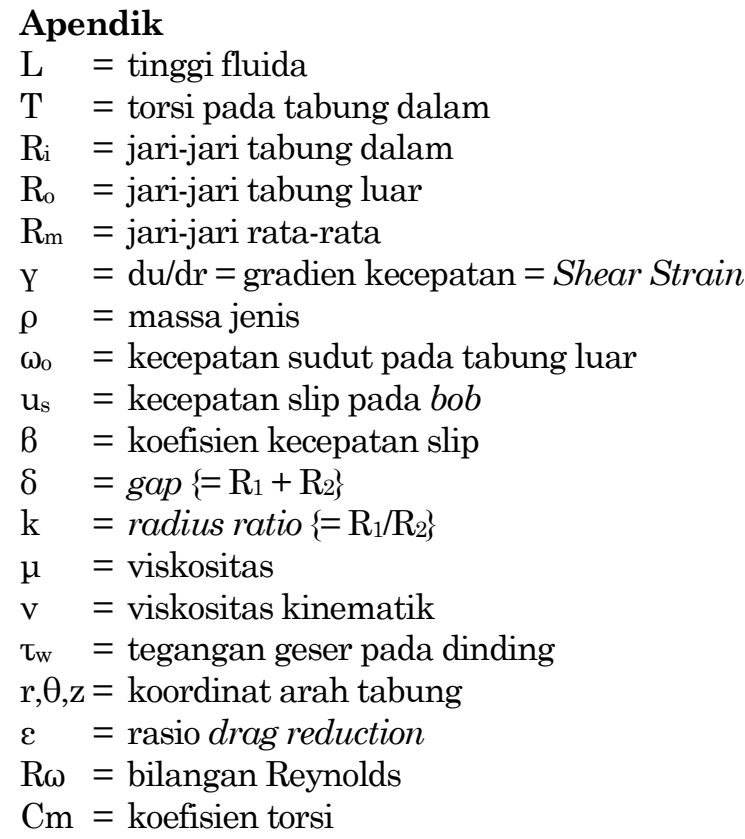




\section{DAFTAR PUSTAKA}

1. Watanabe, K., Yanuar, Mizunuma H., Drag Reduction in Flow Through Square and Rectangular Ducts with Highly Water-Repellent Walls, FED-Vol. 237, ASME FED Conf. Vol. 2, pp. 115-119. 1996.

2. Watanabe, K., Yanuar, and Udagawa, H., Drag Reduction of Newtonian Fluids in a Circular Pipe with Highly Water-Repellent Wall, Journal of Fluid Mechanics, Vol. 381, pp. 225-238. 1999.

3. Yamada, Y., et al., Viscous Frictional Moment between eccentric Rotating Cylinder when Outer Cylinder rotates, Transactional of JSME (in Japanese), Vol. 35, No. 269, pp. 89-96. 1969.

4. Nouri, J. M., and Whitelaw, J. H., Flow of Newtonian and Non-Newtonian Fluids in a Concentric Annulus with Rotation of The Inner Cylinder, ASME journal of Fluid Engineering, Vol. 116, No. 4, pp. 821-827. 1994.
5. Watanabe, K., Takasi Akino, Drag Reduction in Laminar Flow Between Two Vertical Coaxial Cylinders, Journal of Fluids Engineering. Vol. 121. pp. 541-547. Sept. 1999.

6. Watanabe, K., Yanuar, Udagawa, H., Drag Reduction of Newtonian Fluids in a Circular Pipe with Highly Water-Repellent Walls. The 3rd International Symposium on Performance Enhancement for Marine Applications. Newport, Rhode island, pp.157-162. 1997.

7. Larson. R G., Eric S G., Shaqfeh and Muller S J., A purely elastic instability in Taylor_Couette flow. Journal of Fluids Mechanics. Vol. 218. pp. 573600. 1990.

8. Navier, C.L.M.H., Memoires de L'Academie Royale des Sciences de L'Institut de France. Vol. 1, pp. 235-258. 1816. 